\title{
Measuring the Performance of Logistics Industry in the Context of Karachi
}

\author{
Ifrah Quais*, Danish Ahmed Siddiqui \\ Karachi University Business School, University of Karachi, Pakistan \\ ifrahqais@hotmail.com*, Daanish79@hotmail.com
}

\begin{abstract}
The Freight Forwarding and Logistics industry play a vital role in the overall economy of Pakistan. The purpose of this study is to determine the effect of the dynamic capabilities, services, capabilities, competitive advantage, and information sharing capabilities on organizational performance in the logistics industry in Karachi, Pakistan. Dynamic capabilities, services, capabilities, competitive advantage, and information sharing capabilities hypothesized as positively impacting on organizational performance. An online survey was conducted and the data were obtained from a sample size of 100 full time and part time employees from the logistics industry in Karachi. We performed multiple regression analysis to indicate all factors significant impact on organizational performance. Reliability test was also performed which showed that our study is significant. Conducting the research in a city with low literacy rate and low employee growth rate resulted in a small sample size because many people tend not to respond to online surveys.
\end{abstract}

Keywords: Logistics performance, dynamic capabilities, services, capabilities, competitive advantage, information sharing capabilities

\section{Introduction}

Tremendous amount of work (Lai et al., 2008, Kuo et al. 2017, and Mohd et al. 2017) has already been done on performance of the logistics industry in various fields and many of the authors describe the different situations and capabilities that have greater impact on organization performance of the logistics industry and Many of them conducted from different country according to their mindset or philosophy. The aim of this study is to evaluate the relationship with diverse capabilities and organization performance. Illustrate the impact of organizational performance through these Dynamic capabilities, Services capabilities, logistics capabilities, information capabilities and competitive advantage. As a logistics hub of global importance, Pakistan also been providing world-class logistics services and enjoys many advantages to sustain this position and take part in the global marketplace on having the "right" logistics by eliminating wastage and makes available the right product at the right time. (Hajiesmaeili el at. 2016) it is scrutinized that logistics performance have influences on the organizational performance. Working to the right line of logistics or selecting it according to the priorities of the firm give best result to the organization performance. Providing good quality and services to the customer it is also a main function in the firm which are done by supply chain and in more with the help of logistics. (Agrawal el at. 2015). interlink with of Logistic Service Providers (LSPs) with global study on the capabilities and performance characteristics. Organization performance deals with operations, information technology and dynamic capabilities as well as financial. The firm's size delineate overall results focus between the different capabilities on the performance of the organization which set of expand the function of Logistics services capability. Main important factors of freight forwarding firm to afford the need of specific services customer, ability to transport the material or to provide warehouse space.

According to Tsamenyi et al. 2010 organizational performance has been described as the cover of a firm's efficiency, which is different from target achievement. There are five dimensions of a balanced business scorecard that consist of a financial dimension (profits, sales growth, and expense growth), an internal business dimension, a customer perspective (customer satisfaction, service quality, and market share), a learning and growth perspective (employee job satisfaction, and employee training) and a community perspective (corporate reputation). (Green et al. 2008) a supply chain focus consequence in get better logistics performance, which in turn led to progress organizational performance. Logistics performance is positively impacted by supply chain management strategy and directly impacts marketing performance, which, in turn, impacts financial performance Logistics is the main function of supply chain that link together for the best outcome. (Stank et al. 2001) Logistics is a competency within supply chain management, which possesses both strategic and structural capabilities that are focused exclusively on managing the activities solely used to fulfill customer orders. (Knee, 2001) A freight forwarder is an intermediary linking a shipper 
(e.g. An electronics manufacturer exporting semiconductor) to an airline, shipping line or trucking firm and/or linking one of those transportation services firms to the consignee. (Meyer et al. 2012) the globalization of business and the increase in competitive stress have prompted many firms to develop logistics as a part of their corporate strategy for cost and service advantages. This research outline provides on five main segments of the paper. Section one presents an overview of all the important elements. Section two provides the literature that is relevant to the selected research variables. Section three presents the research methods along with research and tools that are adopted for this research. Section four shows about the research findings and interpretation of the data findings or results of the data. Section Five presents the conclusion, recommendations, further research implication and limitations based on research findings.

\section{Literature Review}

Dynamic Capabilities: Teece (2007) defines the concept of "dynamic capabilities" as the firm's ability to integrate, build, and reconfigure internal and external competencies to address rapidly changing environments. The brass tacks of dynamic capabilities are the individual skills, processes, procedures, organizational structures, decision rules, and disciplines. (Zollo \& Winter, 2002) Organization activity generate its operating routines in pursuit of improved effectiveness. The ability to plan and effectively execute post acquirement integration processes is another example of a dynamic capability. (Wang et al. 2007) Strategic management gives the indication about dynamic capabilities that are associated with superior firm performance to enable a quick response to changes in the business environment and influence in the organization performance with better knowledge. Tsekouras et al. (2011) examined on the small companies in a traditional to develop service sector the types and the nature of innovations by, as well as the ways that innovations impact their strategic capabilities which very power of changing journey. (Cepeda \& Vera, 2007) amplification of the link between operational (how you earn your living) capabilities and dynamic (how you change your operational routines) capabilities. (Wamba et al. 2017) he studies examine on firm performance as well as the arbitrate effects of process-oriented dynamic capabilities on the relationship between them. Data collected from 297 Chinese IT managers and business analysts with big data and business analysis experience. The results show that all the causal links cited by both Dynamic capabilities and firm performance explain $65 \%$ of the variance of FPER in which $30 \%$ of the variance is explained by the mediator.

Hypothesis 1: Dynamic capabilities are positively related to organizational performance in the Logistics industry.

Competitive Advantages: (Halilović \& Ilgun, 2014) competitive advantages give unique points from the competitors. Firm acing uncertain environments, to achieve greater supply chain teamwork to influence the resources and knowledge of their suppliers and customers. (Talaja, 2012) analyzes the organization performances have impact of competitive advantage by characteristics of resources and capability. The companies with more valuable and rare resources achieve higher levels of sustainable competitive advantage and performance. (Cheng \& Yeh, 2007) the key capabilities are composed of company scale and information equipment, relationship with competitors, clients, upstream and downstream partners and corporate reputation and past delivery. Internal allocations of resource and staff capabilities are the competitive advantage. (Wong \& Le Chong, 2016) challenges faced by third party logistics (3PL) with the fast dismantling of economic barriers, brutal global competition, immovable economic uncertainties and delicate balancing of a sustainable differentiated consumption and low cost production. The questionnaires concerned 163 valid responses and sustainable pathways through the firm's 3PL. Lower cost as the metric of competitive advantage by different systems. (Gimenez \& Ventura, 2003) analyzing the relationship between internal and external integration processes, their effect on firms' performance and their contribution to the achievement of a competitive advantage. The resulting sample had 199 manufacturers and analyzed through costs, stock out and lead time reductions. And, the achievement of a better competitive position is measured by comparing the firm's performance with its competitors' performance.

Hypothesis 2: Competitive Advantages is positively related to organizational performance in the Logistics industry.

Services Capabilities: (Huang et al. 2015) Service capabilities refer to "the process of delivering products in a way that creates added value to customers. The key factors found in Service capabilities have to fully 
satisfying customers' increasing requirement in container shipping. Implementation of ISO standard may ensure the confidence of the customer for liner shipping services. (Kent \& Parker, 1999) services capability has same important attributes were claims processing, pickup and delivery service, special equipment, line haul services, and quality of carrier salesmanship. Moving good from start point to end consumer it all depend what service are providing them to get best result. (Oh \& Kim, 2017) aims to evaluation Service quality in the hospitality and tourism field which have a strong impact on organizational performance. Services qualities have many different models to elevate but one of that is customer value which is given to the customer and what end customer get behind that internal services should work in good flow. (Hinkin \& Tracey, 1998) Organization meet combines intangible service with tangible products and facilities. Resulting depend upon analyzing by different service factors are safety, security, training may impact on performances. Meeting effectiveness of organization identifies a comprehensive set of physical and service-related characteristics. (Yang \& Peterson, 2003) Quality services in realm of the context of Internet retailing. Data gathering by analyzing 1,078 consumer stories of online shopping experiences. Main service-quality factors determine responsiveness, credibility, ease of use, reliability, convenience, communication, access, competence, courtesy, personalization, continuous improvement, collaboration, security/privacy and aesthetics. (Huang et al. 2015) The empirical study is performed to investigate service quality of Asian liner shipping industry by focusing on a group of nameless leading liner shipping companies. The survey data were collected through e-mail, interview or personal visit. One of the major findings is the customer of liner shipping service tends to purchase a complete transport service including other logistics services. The important technical measures are the implementation of the ISO 9001 framework, cheaper service and exemption of terminal handling fee.

Hypothesis 3: Services Capabilities are positively related to organizational performance in the Logistics industry

Information sharing capabilities: (Lai et al. 2008) the electronic integration impact on business processes of organizational performance in terms to reduce logistics cost and service improvements. Resources for the company are information gathering and finance knowledge to perform logistic activities. (Kawasaki et al. 2011) information and Communication Technology (ICT) that becomes competitive in the logistics market that value for customers and other stakeholders in the way to give benefits cost reduction and better service to the customer. (Hsu et al. 2009) information technologies are used at every point of life and in organization it playing a vital role. In logistic, importing a cargo needed to construct a network of information and human flows for the customs clearance.

Information Sharing Capability: (Shu-Mei, 2017) Firm is facing the complexity in the business processes, trying to find ways to improve performance. The result of a survey of 130 firms in Taiwan confirmed the mediating role of operational capabilities. Method to enhance the IQ of enterprise applications are information completeness, information accuracy, information format, and information currency constitutes the construct information quality. (Mohd el at. 2017) Road logistics, transportation need mobility medium to run a business process. Delivery delay and rising costs are the two major effects of business performance for logistics service providers (LSPs). This study is based on empirical data gathered from 81 LSPs in the East Coast region registered with the Federation of Malaysian Manufacturers directory of Malaysian industries. (Benitez-Amado \& Ray, 2013) explores that information technology (IT) infrastructure affects firms' ability to brains and grab Merger and Acquisition (M \&A) opportunities and integrate acquisitions. Data collected as matched-pair survey data from 100 mid-size Spanish firms using a combination of secondary as well as. Development of business flexibility and IT integration capability, a flexible IT infrastructure enables firms to chase M\&A opportunities and facilitates the integration of IT and business resources of the merged firm to help realize the economic benefits.

Hypothesis 4: Information Sharing capabilities are positively related to organizational performance in the Logistics industry 


\section{Conceptual Framework}

\section{Independent Variables}

H1=Dynamic Capabilities

$\mathrm{H} 2=$ Competitive Advantage

H3=Services Capabilities

H4=Information Sharing Capabilities

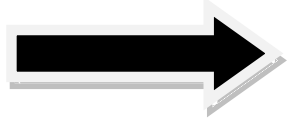

Dependent Variable

Organizational Performance

\section{Methodology}

It is the industrial research and data depend upon the primary data source. A well-designed questionnaire, which incorporated all the selected variables, is used to collect data for this research study by means of a questionnaire survey. The questionnaire survey for this research study was administered among the population of freight forwarding and logistics industry people in Karachi. The large number of information collects in short time with the help of Google drive. In this, structured questionnaire developed and which is close-ended question using the Likert scale which was used to indicate the level of responses to all items; $1=$ strongly disagree, $2=$ disagree, $3=$ Neutral, $4=$ agree, 5 strongly agree (Likert, R., 1932). The questionnaire work on analyzing and designed to find factors influencing to organizational performance. Dynamic capabilities - Dynamic capabilities were measured as respondents' employing companies'/agencies' ability to integrate, build and reconfigure their competences to face a changing environment. The 3 measurement items were adapted from Lin and $\mathrm{Wu}(2014)$.

Service capabilities: Service capabilities of respondents' employing container shipping companies/ agencies were measured using 3 items adapted from the study of Yang et al. (2009).

Competitive advantage: Competitive advantage was measured by respondents identifying specific competitive advantage in their employing companies/agencies. 3 measurement items were adapted from Schilke (2014).

Information Sharing Capabilities: Information sharing capabilities play a fundamental role in the delivery of logistic services, in particular real time visibility into processes and data. The capabilities also relate heavily to the interconnectivity to its customers and its resources. 3 measurement items were adapted from Sandberg \& Abrahamsson (2011).

Organizational Performance: Organizational performance was measured by respondents identifying specific organizational performance in their employing companies/agencies. 3 measurement items were adapted from Tsamenyi et al. (2010).

The questionnaire was sent through email messages to the 250 employees of different companies who belonged to the logistics/ freight forwarding industry in Karachi and 100 responded back having a response rate of $40 \%$. The measurement scales are separately tested for their reliability and validity. The answers of the respondents were after collection, processed into SPSS and different analysis and tests were performed such as reliability test, factor analysis and regression analysis to find out the reliability of the data, the relationship between the variables and the authenticity of the items of each variable.

Regression Equation: The Regression Equation for this model is as below;

$$
O P=\alpha_{0}+\beta_{1} D C+\beta_{2} S C+\beta_{3} C A+\beta_{4} I S C+e
$$

Where,

$\boldsymbol{\alpha}_{0}=$ is the intercept

$\boldsymbol{\beta}=$ are the regression coefficients for all independent variables.

$\mathrm{DC}=$ Dynamic capabilities, which were measured as respondents' employing companies'/agencies' ability to integrate, build and reconfigure their competences to face a changing environment. The 3 measurement items were adapted from Lin and $\mathrm{Wu}(2014)$.

$\mathrm{SC}=$ Service capabilities, respondents of employing Logistics industry were measured using 3 items adapted from the study of Yang et al. (2009).

$\mathbf{C A}=$ Competitive advantage, was measured by respondents identifying specific competitive advantage in their employing companies/agencies. 3 measurement items was adapted from Schilke (2014). 
ISC = Information Sharing Capabilities, play a fundamental role in the delivery of logistic services, in particular real time visibility into processes and data. The capabilities also relate heavily to the interconnectivity to its customers and its resources. 3 measurement items were adapted from Sandberg \& Abrahamsson (2011).

$\mathbf{O P}=$ Organizational Performance, was measured by respondents identifying specific organizational performance in their employing companies/agencies. 3 measurement items were adapted from Tsamenyi et al. (2010).

\section{Results and Empirical Analysis}

Findings and Interpretation of the Results: In this section we analyzed factors that influence organizational performance of freight forwarding/logistics industries in context of Karachi.

Table 1: Distributions of Questionnaires

\begin{tabular}{ll}
\hline Items & Number \\
\hline Questionnaires distributed & 250 \\
Total response & 120 \\
Unusable response & 20 \\
Usable response & 100 \\
Total response rate & $40 \%$ \\
\hline
\end{tabular}

Table 2: Profile of the respondents

\begin{tabular}{lll}
\hline Respondent's Profile & Categories & Percent \% \\
\hline \multirow{3}{*}{ Company } & Multinational & 97.2 \\
Job title & Local & 2.8 \\
& Manger & 60.8 \\
Work experience & General Employees & 39.2 \\
& 2-5 years & 39.6 \\
& 6-10 years & 37.1 \\
Length of business organizational & 10 years or above & 23.3 \\
& 3-5 years & 8.3 \\
& 6-10 years & 8.3 \\
& 11-20 years & 45.4 \\
& 21 years or above & 38.1 \\
\hline
\end{tabular}

The industry wide survey was completed by 100 employees from various logistics/freight forwarding organization in Karachi. As regards ownership pattern, almost hundred (97.2\%) of respondents' employing firms were multinational owned, and $2.8 \%$ were local owned. The profile of respondents shows that $60.8 \%$ were managers and $39.2 \%$ were general employees. This oblique that most respondents had abundant practical experience and a high enough position to answer questions with respect to dynamic capabilities, service capabilities, competitive advantage, information sharing capabilities and organizational performance. With regard to length of work experience in their employing company, 39.6\% respondents to $2-5$ years, where else $37.1 \%$ respondents had worked at their company for $6-10$ years and $23.3 \%$ were 10 years or above. Respondent's rates the length of business organizational $8.3 \%$ were the 3-5years and 6-10 years, $45.4 \%$ were the $11-20$ years of business organizational length and $38.1 \%$ were 21 years or above. 
Table 3: Reliability Statistics

\begin{tabular}{lll}
\hline Variables & Cronbach's alpha & N of items \\
\hline DC & .847 & 3 \\
SC & .619 & 3 \\
CA & 1.000 & 3 \\
ISC & .620 & 3 \\
OP & .684 & 3 \\
Overall Reliability & .881 & 15 \\
\hline
\end{tabular}

Table 3 provides Reliability test is used to check the reliability and validity of data collected through questionnaires. It checks the consistency and accurateness in answers collected. The value of Cronbah's alpha for the entire variable which is 0.881. It appears from the table that the values of Cronbach's alpha of DC,SC,CA,ISC and OP range from 0.6 to 1.0. Thus it can be concluded that the measures have an acceptable level of reliability.

Table 4: KMO and Bartlett's Test

\begin{tabular}{ll}
\hline Kaiser-Meyer-Olkin Measure of Sampling Adequacy & $\mathbf{0 . 7 4 9}$ \\
Bartlett's Test of Sphericity & \\
Approx. Chi-Square & 2776.459 \\
Degree of freedom & 171 \\
Sig. value & .000 \\
\hline
\end{tabular}

Table 4 shows the Kaiser Meyer-Olkin Measure of Sampling Adequacy (KMO) for this study was high as 0.749 whereas Bartlett's Test of Spehricity was significant.

Table 5: Factor Analysis of Correlation Matrix

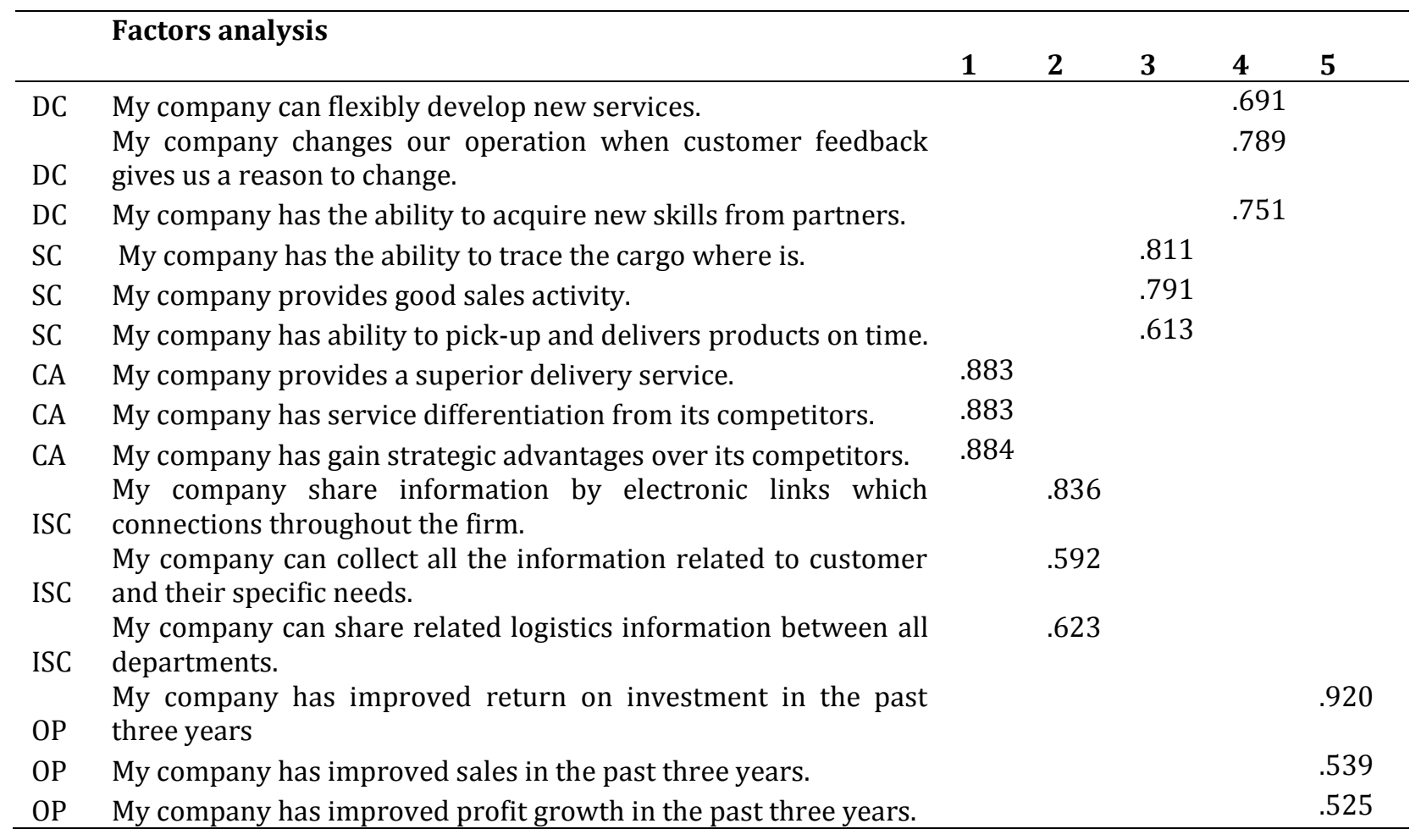


Table 5 illustrates all variables that are Dynamic capabilities, services capabilities, Competitive advantage, Information Sharing capabilities and Organizational performance. To obtain the concrete result of grouping, a factor analysis was conducted and we rotated the factors by using varimax method to simplify our results interpretation and all items were scrutinized for patterns through factor analysis. Table 5 illustrates rotated component matrix. When loading less than 0.40 were excluded, analysis resulted a five factor solution with a simple structure (factor loadings $>0.40$ ). Three items loaded onto Factor 1 which is related to competitive Advantage. Three items loaded onto Factor 2, represented information sharing Capabilities whereas three items loaded onto factor 3, resulted in Services Capabilities. Three items loaded onto Factor 4 which is about Dynamic Capabilities. Lastly three items loaded onto Factor 5 representing Organizational Performance.

Table 6: Regression Analysis

\begin{tabular}{lllll}
\hline Variables & Coefficient & T.STATS & PROB. VALUE & VIF \\
\hline Constant & 1.11 & 3.61 & .000 & \\
DC & .024 & .363 & .718 & 2.22 \\
SC & .420 & 4.69 & .000 & 1.86 \\
CA & .035 & .412 & .681 & 2.88 \\
ISC & .286 & 3.55 & .001 & 2.43 \\
R Square & & .591 & & \\
F-Statistics & & 34.26 & & \\
Probability (F-Stat) & & $.000^{\mathrm{b}}$ & & \\
\hline
\end{tabular}

A multiple linear regression test was performed to examine the relationship between Organizational performance and dynamic capabilities, services capabilities, competitive advantage, information sharing capabilities. Variance Inflation Factor (VIF) in our study for all four independent variables is low 2.25, 1.86, 2.80 and 2.43 this leads to the result that multicollinearity does not exist. R square shows the dependent variable variance explained in context independent variable. 0.591 is the value of $\mathrm{R}$ square, which means that $59.1 \%$ variation in organizational performance being the dependent variable is explained by the independent variables (dynamic capabilities, services capabilities, competitive advantage and information sharing capabilities). Value of coefficient or slope represents the relationship between the variables. With the demographic variables included Table 6 illustrates the results of regression analysis which clearly depicts that coefficients of dynamic capabilities $(\beta=.024)$, services capabilities $(\beta=.420)$, competitive advantage $(\beta=$ $.035)$ and information sharing capabilities $(\beta=.286)$ are positive and there is a positive relationship between dependent variable (Organizational Performance) and Independent variable (dynamic capabilities, services capabilities, competitive advantage and information sharing capabilities). As we already know that in multiple linear regressions, the sign of coefficient whether it is negative or positive give us the direction of the effect. We can clearly observe that Significance F value is less than 0.1 which states that combine effect of all independent variable is significant. According to the results obtained, regression equation is as follows;

$$
O P=1.11+(.024) D C+(0.420) S C+(.035) C A+(.286) I S C
$$

To better understand this study, Table VI results showed that dynamic capabilities has a positive but insignificant $(\beta=0.024, p>0.1)$ impact on organizational performance thus failing to support the hypothesis H1. Services capabilities also has a positive and significant $(\beta=.420, p<0.1)$ impact on organizational performance thus supporting the hypothesis $\mathrm{H} 2$. Competitive advantage also has a positive but insignificant $(\beta=.035, \mathrm{p}>0.1)$ impact on organizational performance thus failing to support the hypothesis $\mathrm{H} 3$. Information sharing capabilities also has a positive and significant $(\beta=.286, p<0.1)$ impact on organizational performance thus supporting the hypothesis H4. The above equation is interpreted as: 1 percent of the organizational performance increase, if the dynamic capabilities are increased by 0.024 percent. The organizational performance increases by 1 percent, if the services capabilities are increased by 0.420 percent. The organizational performance increases by 1 percent, if the competitive advantage is increased by 0.035 
percent. The organizational performance increases by 1 percent, if the information sharing capabilities are increased by 0.286 percent.

Table 7: Hypothesis Assessment Summary

\begin{tabular}{ll}
\hline Research Hypothesis & Results \\
\hline H1 = Dynamic capabilities has an insignificant effect on organizational performance. & Rejected \\
H2= Competitive advantage has an insignificant effect on organizational performance. & Rejected \\
H3= Services Capabilities has a significant effect on organizational performance. & Accepted \\
H4= Information sharing capabilities has a significant effect on organizational performance. & Accepted \\
\hline
\end{tabular}

In Karachi, companies are suffering from insufficient resources; in which some they are human knowledge, technologies and information materials to cope with different environment in the market. In companies employees are not well trained to manage the situation. Competitive advantage is neglect due to not working in strategies based on the resources. Companies do not have such kind of resources and capabilities to exploit opportunities to beat the market. They do not pitch up by differentiate them each other. Another reason is that, sometime companies do not approach right customer due to that they failed to achieve competitive advantage. Sometime, culture of the organization causes failure of these things by not changing environmental work place.

\section{Conclusion}

This study investigated the linkages between dynamic capabilities, service capabilities, competitive advantage, information sharing capabilities and organizational performance in the freight forwarding industry. The Logistics Industry plays an important role in Pakistan's economy. Karachi is the main city for moving goods towards other countries. As Karachi has seaports, airports and the most benefiting sectors is the road transportation logistics that in turn somehow created unwanted road congestions as a by-product of its development, particularly affecting urban areas. Working in the right line of logistics or selecting it according to the priorities of the firm give the best result in the organization performance. Providing good quality and services to the customer it is also a main function in the firm which are done by supply chain and in more with the help of logistics sectors. In service industry, it is one of the biggest challenges in providing relevant service to customers is very important. Identifying customers' needs and rapidly fulfilling they can bring about positive and fruitful outcomes. It is proved from the analysis that information sharing capabilities and services capabilities have a positive and significant impact on organizational performance. Whereas, dynamic capabilities and competitive advantage have insignificant impact on organizational performance. Meeting effectiveness has impact on physical and service-related uniqueness of properties that is an important. Regarding service capabilities attribute, respondents strongly agreed that they are good to trace out the cargo in where point of movement, have abilities to pick up and deliver the goods on time which provides good sales activity.

Information sharing plays an excellent role organizational performance in terms to reduce logistics cost and service improvements. By electronic link company share information which connections throughout the firm, collect all the information related to customer and their specific needs and share related logistics information between all departments. Competitive advantages give unique points from the competitors. The organization always wants to achieve competitive advantage in that they have to improve organizational performance. Dynamic capabilities, ability to integrate, build and reconfigure their competences to face a changing environment, but some time the company fails on it. Failure of dynamic profit margins and competitive advantage its effect on organization, the target profit effect on profit margin of the organization and when it not getting target profit they start fire employees and sometime they do from top level manager who have great experience relocate them, reprimand them, and make their lives unpleasant. Sometime, it arises threat to the organization. It is the main reason that few companies are working in good path and the rest of them are running out of it.

Recommendations and Policy Making: We recommend that organizations and higher level managers should make strategies for Competitive advantages. A company should focus to have ability to provide 
superior delivery services, gain strategic advantage over its competitors. The company should have characteristics of resources and capability to attract more potential customer and expand the market share with the help of Porter's cost leadership strategy which may be the best choice for regarding select the mode of transportation. Employees usually come from a middle class background in logistics industry of Karachi so they tend to majorly emphasize on the salary they get because at the end they run their family and that effect the performances of the organization. Employees don't have such knowledge about how to work out according to the dynamic changes. For that organizational have to trainee and give some class to their employees regarding, the need of specific services, customer and taking feedback from the customer so companies can better understand the changes need in the operation. By attending seminars or workshop which helps the Organization to learn from partners about changes or new development acquiring in the market.

Thus we recommended that the organization should conduct monthly feedback sessions with each employee to discuss the issues facing in the operation of the organization. There should be a collaborative committee in the organization that must ensure to conduct for sharing different experiences faced which can improve the performance organization. To set the direction of success of the organizations, they should conduct weekly team meetings to put light on the daily work load and exceptions that employee is facing, when the targets are assisted timely. Monthly organizational meetings should be conducted to discuss the current performance of the organization, the future targets to achieve and proper goal setting on departmental level and individual level. The organization should Removes inefficiencies to embrace and encourage failure; they will be able to more effectively eliminate projects and initiatives before they suck up any more resources.

Limitations and direction for future research: In Pakistan, supply chain industry is still evolving and there are very few companies in Karachi who are engaged in Supply Chain activities. Thus we were not able to reach other companies in many different cities. There are many challenges faced by logistics industry. The organization always wants to achieve competitive advantage in that they have to improve organization which creates devotion on overall performances. This study has several limitations and can be suggested for future research. First, this study has demonstrated that dynamic capabilities are needed and should be especially stressed in a situation of environmental dynamism. However, in order to prove that this is also useful in the other parts of the world, it would be valuable to collect data from other regions or cities in Pakistan to obtain a balanced view of the relationships between dynamic capabilities, service capabilities, competitive advantage, information sharing capabilities and organizational performance in operations of the logistics industry. Thus, future research will be investigated on technologies and software application on logistics performances of the organization. Also approach to identify the priorities of strategic choices. More work on overall main cities of Pakistan.

\section{References}

Agrawal, S., Singh, R. K., \& Murtaza, Q. (2015). A literature review and perspectives in reverse logistics. Resources, Conservation and Recycling, 97, 76-92.

Benitez-Amado, J., \& Ray, G. (2013). Impact of Information Technology Infrastructure Flexibility on Mergers and Acquisitions.

Cepeda, G., \& Vera, D. (2007). Dynamic capabilities and operational capabilities: A knowledge management perspective. Journal of Business Research, 60(5), 426-437.

Cheng, Y. H., \& Yeh, C. Y. (2007). Core competencies and sustainable competitive advantage in air-cargo forwarding: evidence from Taiwan. Transportation Journal, 5-21.

Gimenez, C., \& Ventura, E. (2003). Supply chain management as a competitive advantage in the Spanish grocery sector. The International Journal of Logistics Management, 14(1), 77-88.

Green Jr, K. W., Whitten, D., \& Inman, R. A. (2008). The impact of logistics performance on organizational performance in a supply chain context. Supply Chain Management: An International Journal, 13(4), 317-327.

Hajiesmaeili, A., Rahimi, M., Jaberi, E., \& Hosseini, A. A. (2016). Studying the Influence of Logistics on Organizational Performance through a Supply Chain Strategy: Case Study in Goldiran Electronics Co. World Academy of Science, Engineering and Technology, International Journal of Social, Behavioral, Educational, Economic, Business and Industrial Engineering, 10(4), 1042-1050. 
Hajiesmaeili, A., Rahimi, M., Jaberi, E., \& Hosseini, A. A. (2016). Studying the Influence of Logistics on Organizational Performance through a Supply Chain Strategy: Case Study in Goldiran Electronics Co. World Academy of Science, Engineering and Technology, International Journal of Social, Behavioral, Educational, Economic, Business and Industrial Engineering, 10(4), 1042-1050.

Halilović, A., \& ILGUN, E. (2014). The Impact of Supply Chain Management Practices on Competitive Advantage and Organizational Performance; Case: Companies in Bosnia and Herzegovina. In International Conference on Economic and Social Studies. International Burch University.

Hinkin, T. R., \& Tracey, J. B. (1998). The service imperative: Factors driving meeting effectiveness. The Cornell Hotel and Restaurant Administration Quarterly, 39(5), 59-67.

Hsu, C. I., Shih, H. H., \& Wang, W. C. (2009). Applying RFID to reduce delay in import cargo customs clearance process. Computers \& Industrial Engineering, 57(2), 506-519.

Huang, S. T., Bulut, E., \& Duru, O. (2015). Service quality assessment in liner shipping industry: an empirical study on Asian shipping case. International Journal of Shipping and Transport Logistics, 7(2), 221-242.

Huang, S. T., Bulut, E., \& Duru, O. (2015). Service quality assessment in liner shipping industry: an empirical study on Asian shipping case. International Journal of Shipping and Transport Logistics, 7(2), 221-242.

KAWASAKI, T., HANAOKA, S., \& LE, H. T. (2011). The Impact of Information and Communication Technology on Performance of Logistics Service Providers in Vietnam. The impact of information and communication technology on performance of logistics service providers in Vietnam, (44).

Kent, J. L., \& S. Parker, R. (1999). International containership carrier selection criteria: shippers/carriers differences. International Journal of Physical Distribution \& Logistics Management, 29(6), 398-408.

Knee, R. (2001). Mergers in transit. Logistics Management and Distribution.

Kuo, S. Y., Lin, P. C., \& Lu, C. S. (2017). The effects of dynamic capabilities, service capabilities, competitive advantage, and organizational performance in container shipping. Transportation Research Part A: Policy and Practice, 95, 356-371.

Lai, K. H., Ngai, E. W. T., \& Cheng, T. C. E. (2002). Measures for evaluating supply chain performance in transport logistics. Transportation Research Part E: Logistics and Transportation Review, 38(6), 439456.

Lai, K. H., Wong, C. W., \& Cheng, T. E. (2008). A coordination-theoretic investigation of the impact of electronic integration on logistics performance. Information \& Management, 45(1), 10-20.

Li, S., Ragu-Nathan, B., Ragu-Nathan, T. S., \& Rao, S. S. (2006). The impact of supply chain management practices on competitive advantage and organizational performance. Omega, 34(2), 107-124.

Likert, R. (1932). A technique for the measurement of attitudes. Archives of psychology.

Lin, Y., \& Wu, L. Y. (2014). Exploring the role of dynamic capabilities in firm performance under the resourcebased view framework. Journal of business research, 67(3), 407-413.

Meyer, J. P., Stanley, D. J., Jackson, T. A., McInnis, K. J., Maltin, E. R., \& Sheppard, L. (2012). Affective, normative, and continuance commitment levels across cultures: A meta-analysis. Journal of Vocational Behavior, 80(2), 225-245.

Mohd, N. F. B., Wahab, S. A., Al Mamun, A., Ahmad, G. B., \& Fazal, S. A. (2017). Logistics Capability, Information Technology, and Innovation Capability of Logistics Service Providers: Empirical Evidence from East Coast Malaysia. International Review of Management and Marketing, 7(1).

Mohd, N. F. B., Wahab, S. A., Al Mamun, A., Ahmad, G. B., \& Fazal, S. A. (2017). Logistics Capability, Information Technology, and Innovation Capability of Logistics Service Providers: Empirical Evidence from East Coast Malaysia. International Review of Management and Marketing, 7(1).

Oh, H., Oh, H., Kim, K., \& Kim, K. (2017). Customer satisfaction, service quality, and customer value: years 2000-2015. International Journal of Contemporary Hospitality Management, 29(1), 2-29.

Sandberg, E., \& Abrahamsson, M. (2011). Logistics capabilities for sustainable competitive advantage. International Journal of Logistics Research and Applications, 14(1), 61-75.

Schilke, 0. (2014). On the contingent value of dynamic capabilities for competitive advantage: The nonlinear moderating effect of environmental dynamism. Strategic Management Journal, 35(2), 179-203.

Shu-Mei Tseng (2017)"How Information Quality Leads to Operational Capabilities and Corporate Performance." source: International Journal of Innovative Science, Engineering and Technology (IJISET) 4 (2017): 26-34.

Stank, T. P., Keller, S. B., \& Closs, D. J. (2001). Performance benefits of supply chain logistical integration. Transportation Journal, 32-46. 
Talaja, A. (2012). Testing VRIN framework: resource value and rareness as sources of competitive advantage and above average performance. Management: Journal of Contemporary Management Issues, 17(2), 51-64.

Teece, D. J. (2007). Explicating dynamic capabilities: the nature and micro foundations of (sustainable) enterprise performance. Strategic management journal, 28(13), 1319-1350.

Torres, A. R., Raitasuo, P., Oliver, Y., \& Kuula, M. Capabilities And Performance Of Logistics Service Providers In Four Countries: Some Preliminary Results.

Tsamenyi, M., Onumah, J., \& Tetteh-Kumah, E. (2010). Post-privatization performance and organizational changes: Case studies from Ghana. Critical Perspectives on Accounting, 21(5), 428-442.

Tsamenyi, M., Onumah, J., \& Tetteh-Kumah, E. (2010). Post-privatization performance and organizational changes: Case studies from Ghana. Critical Perspectives on Accounting, 21(5), 428-442.

Tsekouras, G., Poulis, E., \& Poulis, K. (2011). Innovation and dynamic capabilities in a traditional service sector: evidence from shipping companies. Baltic Journal of Management, 6(3), 320-341.

Wamba, S. F., Gunasekaran, A., Akter, S., Ren, S. J. F., Dubey, R., \& Childe, S. J. (2017). Big data analytics and firm performance: Effects of dynamic capabilities. Journal of Business Research, 70, 356-365.

Wang, E., Klein, G., \& Jiang, J. J. (2007). IT support in manufacturing firms for a knowledge management dynamic capability link to performance. International journal of production research, 45(11), 24192434.

Wong, W. P., Soh, K. L., \& Le Chong, C. (2016). Differentiated service consumption and low cost production: Striking a balance for a sustainable competitive advantage in Malaysia. International Journal of Production Economics, 181, 450-459.

Yang, C. C., Marlow, P. B., \& Lu, C. S. (2009). Assessing resources, logistics service capabilities, innovation capabilities and the performance of container shipping services in Taiwan. International Journal of Production Economics, 122(1), 4-20.

Yang, Z., Peterson, R. T., \& Cai, S. (2003). Services quality dimensions of Internet retailing: An exploratory analysis. Journal of services marketing, 17(7), 685-700.

Zollo, M., \& Winter, S. G. (2002). Deliberate learning and the evolution of dynamic capabilities. Organization science, 13(3), 339-351 